\title{
Feasibility of routine screening for intimate partner violence in public health care settings in Kenya
}

\author{
Chi-Chi Undie \\ Population Council \\ Catherine Maternowska \\ Margaret Mak'anyengo \\ Ian Askew \\ Population Council
}

Follow this and additional works at: https://knowledgecommons.popcouncil.org/departments_sbsr-rh

Part of the Demography, Population, and Ecology Commons, Domestic and Intimate Partner Violence Commons, Family, Life Course, and Society Commons, International Public Health Commons, Maternal and Child Health Commons, and the Women's Health Commons How does access to this work benefit you? Let us know!

\section{Recommended Citation}

Undie, Chi-Chi, Catherine Maternowska, Margaret Mak'anyengo, and lan Askew. 2013. "Feasibility of routine screening for intimate partner violence in public health care settings in Kenya," Final report. Nairobi: Population Council. 
FEASIBILITY OF ROUTINE SCREENING FOR INTIMATE PARTNER VIOLENCE IN PUBLIC HEALTH CARE SETTINGS IN KENYA

CHI-CHI UNDIE ${ }^{1}$, M. CATHERINE MATERNOWSKA², MARGARET MAK'ANYENGO3 ${ }^{3}$, IAN ASKEW 1

${ }^{1}$ Population Council, ${ }^{2}$ Bixby Center for Global Reproductive Health, University of California, San Francisco and UNICEF, ${ }^{3}$ Kenyatta National Hospital
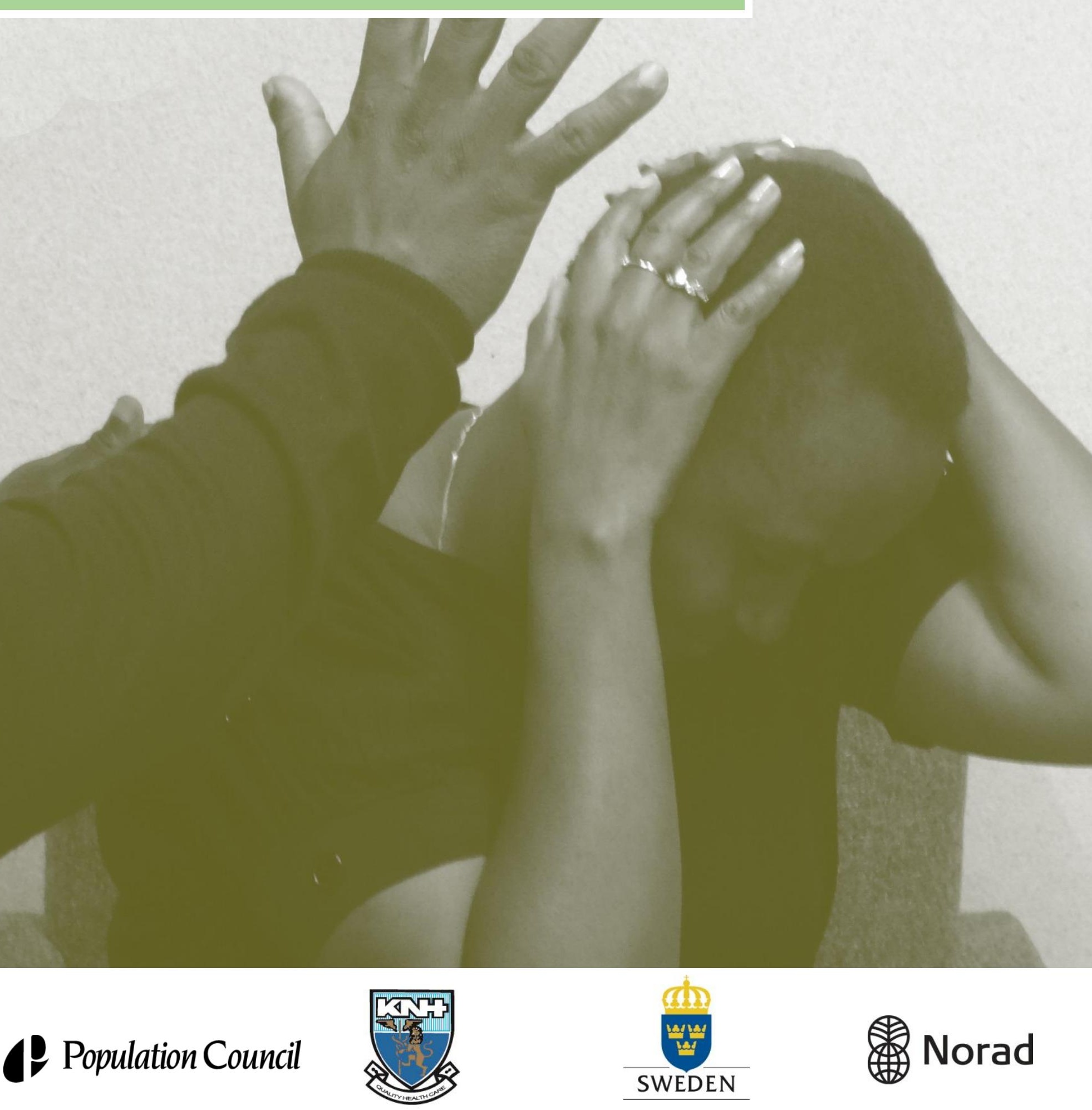
FEASIBILITY OF ROUTINE SCREENING FOR INTIMATE PARTNER VIOLENCE IN PUBLIC HEALTH CARE SETTINGS IN KENYA 


\section{(2) Population Council}

The Population Council confronts critical health and development issues-from stopping the spread of HIV to improving reproductive health and ensuring that young people lead full and productive lives. Through biomedical, social science, and public health research in 50 countries, we work with our partners to deliver solutions that lead to more effective policies, programs, and technologies that improve lives around the world. Established in 1952 and headquartered in New York, the Council is a nongovernmental, nonprofit organization governed by an international board of trustees.

Population Council

Nairobi

General Accident House

Ralph Bunche Road

Nairobi

Kenya

www.popcouncil.org

\section{Suggested citation:}

Chi-Chi Undie, M. Catherine Maternowska, Margaret Mak'anyengo, lan Askew. 2013.

"Feasibility of Routine Screening for Intimate Partner Violence in Public Health Care Settings in Kenya." Nairobi: Population Council.

Cover photo by: Brian Mdawida, Population Council

(C) 2013 The Population Council, Inc. 


\section{TABLE OF CONTENTS}

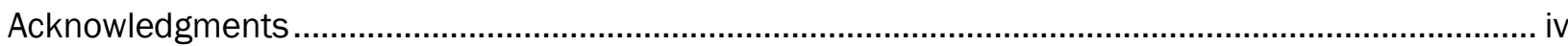

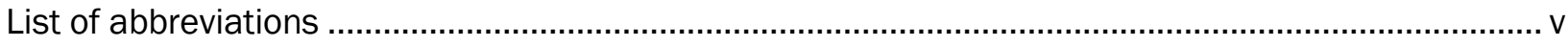

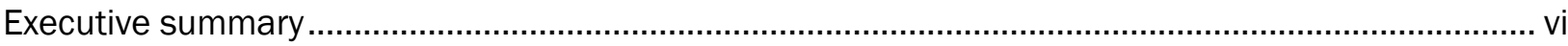

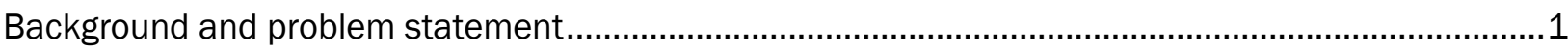

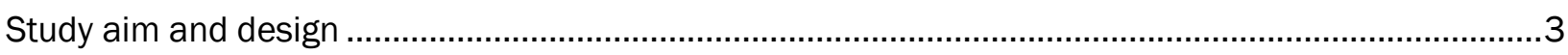

Aim

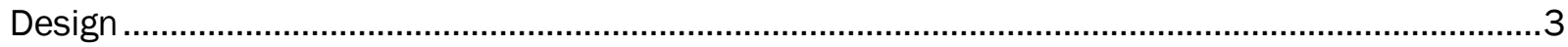

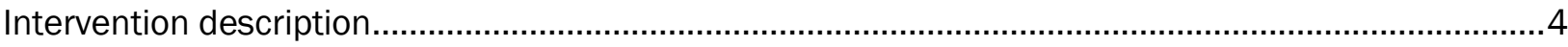

Screening for IPV: Practical issues for consideration ................................................................... 6

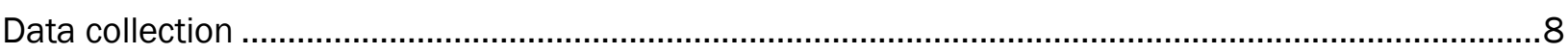

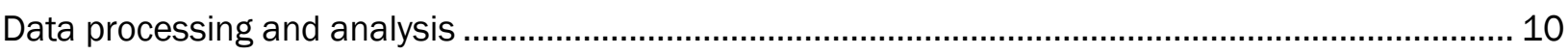

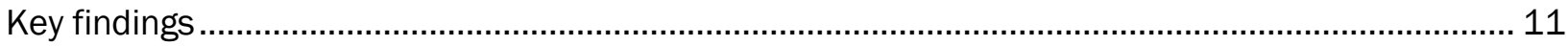

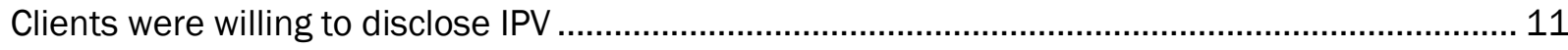

Providers demonstrated capacity to screen for IPV and provide referrals for further care ............. 12

Some providers innovated with the screening process, however.................................................. 13

Male involvement had implications for the screening process...................................................... 14

Referral systems and linkages were found to be largely operational............................................ 14

Resources to protect confidentiality were found to be adequate................................................... 15

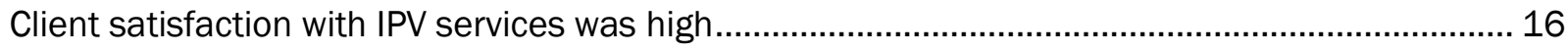

Although referrals were happening, referral uptake was relatively low ........................................ 17

Most clients were willing to comply with referrals for SGBV care ................................................. 17

Non-referral of clients by providers is a barrier to referral uptake ................................................. 18

GBV clinic staff availability is a barrier to referral uptake .............................................................. 19

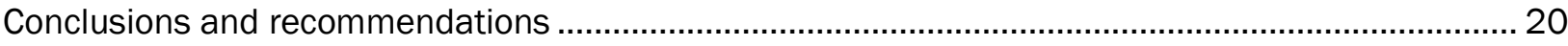

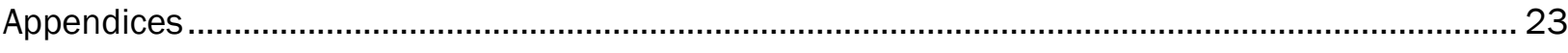

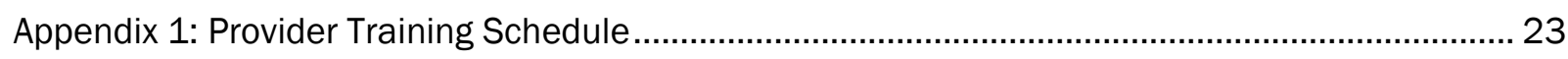

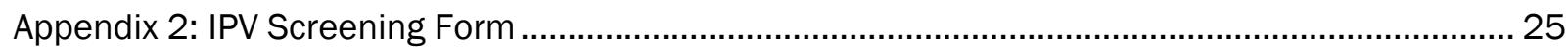

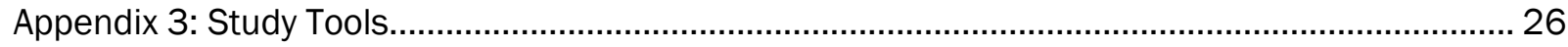

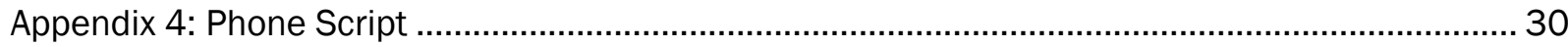




\section{ACKNOWLEDGMENTS}

Financial support from the Swedish-Norwegian Regional HIV and AIDS Team for Africa made this study possible. The study also would have been impossible without the support of Kenyatta National Hospital in carrying out the intervention. We deeply appreciate the leadership of Mr. Richard Lesiyampe, Chief Executive Officer, Kenyatta National Hospital (KNH), and the commitment and contributions of KNH staff from the Antenatal Care Clinic, the Comprehensive Care Centre, the Gender-Based Violence Recovery Centre, and the Youth Centre.

Our study respondents gave generously of their time to participate in the study, and their personal experiences served as an invaluable resource. We are indebted to them, and to: Irene Namai and Janerose Kweyu, the research assistants attached to this project; Susan Chemtai, who served as the project psychologist; and Linda Munyendo, who served as client advocate under the project.

We gratefully acknowledge the invaluable contributions of our Population Council colleagues: Joyce Ombeva for administrative support, and Nancy Termini and Janet Munyasya for formatting the report. 


\section{LIST OF ABBREVIATIONS}

$\begin{array}{ll}\text { ANC } & \text { Antenatal Care } \\ \text { CCC } & \text { Comprehensive Care Centre } \\ \text { FGD } & \text { Focus Group Discussion } \\ \text { GBVRC } & \text { Gender-Based Violence Recovery Centre } \\ \text { HIV } & \text { Human Immuno-Deficiency Virus } \\ \text { IDI } & \text { In-Depth Interview } \\ \text { KNH } & \text { Kenyatta National Hospital } \\ \text { IPV } & \text { Intimate Partner Violence } \\ \text { SGBV } & \text { Sexual and Gender-Based Violence }\end{array}$




\section{EXECUTIVE SUMMARY}

More than a third of women all over the world have experienced either physical and/or sexual intimate partner violence (IPV) or non-partner sexual violence, along with the health consequences that accompany such violence. A recent World Health Organization report indicates that Africa is one region in which the highest prevalence of physical and/or sexual intimate partner violence among ever-partnered women is found.

Routine screening for IPV in carefully selected venues within medical facilities can potentially improve the identification, care, and treatment of violence. However, in African countries, many presumed, untested barriers within health care settings have curtailed opportunities to carry out this sort of screening. This study tested the feasibility of implementing IPV screening protocols in health care settings where sexual and gender-based violence service referrals could be executed.

The study used a descriptive case study design (involving semi-structured, in-depth interviews with clients, focus group discussions with providers, and service statistics) to determine the feasibility of routine screening for IPV. Kenyatta National Hospital (KNH) in Nairobi, Kenya - the oldest and largest public referral hospital in the East African region - served as the study context, with the antenatal care clinic, the HIV Comprehensive Care Centre, the Gender-Based Violence Recovery Centre (GBVRC), and the Youth Centre as the specific KNH study sites.

Providers drawn from these sites were trained to routinely screen for IPV and to refer IPV-positive clients identified through this process to the GBVRC for further care. This intervention occurred over a seven-month period, from June to December, 2012.

In summary, the study found the following:

- Clients were willing to disclose IPV to providers.

- Providers demonstrated capacity to screen for IPV and provide referrals for further care.

- Some providers innovated with the prescribed screening process to align with the realities in their specific departments.

- Referral systems were largely operational.

- Referral uptake by IPV-positive clients was relatively low compared to provider referral rates - an issue that stemmed more from resolvable, systemic barriers than from actual non-compliance with referrals on the part of clients.

- Resources to protect confidentiality while receiving IPV care were perceived as adequate by clients, and client satisfaction with IPV services was high.

- Male involvement in health care settings has implications for IPV screening among women.

This study demonstrates that providers, given the training, are willing and able to incorporate IPV screening into their practice - one that they perform in a severely resource-constrained context. Likewise, the findings indicate that incorporating IPV screening questions into client intake forms in a variety of pubilc health care settings is not only acceptable to clients, but is welcomed as an opportunity to air grievances and trauma. These are initial and important findings and steps forward in the field of violence response and prevention work. 


\section{BACKGROUND AND PROBLEM STATEMENT}

World-wide, well over a third of women have experienced either physical and/or sexual intimate partner violence (IPV) or non-partner sexual violence, along with the health consequences that such violence engenders. ${ }^{1}$ Africa is one region in which the highest prevalence of physical and/or sexual intimate partner violence among ever-partnered women is found, with approximately $37 \%$ reporting ever having had this experience. ${ }^{2}$

Emerging data from countries in East and Southern Africa show high levels of violence against children as well. One of three girls in the region and one of five boys experience some form of sexual violence, for instance, before the age of $18 .{ }^{3}$ Violence in childhood sets a poor precedence for youth entering into relationships later in life and, left untreated, childhood exposure to violence can lead to long-term, abusive relationships, such as IPV. ${ }^{4}$ Ensuring that comprehensive services respond to emergency sexual assaults, as well as to less overt forms of chronic violence (including IPV), is a significant challenge.

Considerable research, generated largely from northern European and American countries, supports the need for routine screening for violence, and specifically for the early detection of chronic IPV. ${ }^{5}$ Most developed countries recommend IPV screening for all women in health care settings. ${ }^{6}$ Recent evidence from Kenya also points to the high acceptability of potential IPV screening interventions from the perspectives of women, youth, and providers alike. ${ }^{7}$

Routine screening for IPV in carefully selected venues within medical facilities can potentially improve the care and treatment of violence in myriad ways: by promoting the early detection of violence, which is important for the reduction of morbidity and mortality in survivors 8 ; by increasing awareness of existing sexual and gender-based violence (SGBV) services, thus

\footnotetext{
1 WHO. 2013. Global and regional estimates of violence against women: prevalence and health effects of intimate partner violence and nonpartner sexual violence. Geneva: WHO

2 Ibid.

3 UNICEF, CDC, MUHAS. 2011. Violence against children in Tanzania: Findings from a national survey, 2009. Summary Report on the Prevalence of Sexual, Physical and Emotional Violence, Context of Sexual Violence, and Health and Behavioural Consequences of Violence Experienced in Childhood. Dar es Salaam, Tanzania: UNICEF Tanzania, Division of Violence Prevention, National Center for Injury Prevention and Control, Centers for Disease Control and Prevention, and Muhimbili University of Health and Allied Sciences, 2011.

4 CDC. n.d. Strategic direction for IPV prevention: Promoting respectful, nonviolent intimate partner relationships through individual, community, and societal change <

http://www.cdc.gov/violenceprevention/pdf/IPV_Strategic_Direction_Full-Doc-a.pdf>.

5 Shears, K.H., Ambasa-Shisanya, C. 2008. Helping victims of sexual coercion. Family Health International.

6 Taft A, O'Doherty L, Hegarty K, Ramsay J, Davidson L, Feder G. 2013. Screening women for intimate partner violence in healthcare settings. Cochrane Database of Systematic Reviews, Issue 4. Art. No.: CD007007. DOI: 10.1002/14651858.CD007007.pub2.

7 Undie C., Maternowska CM, Mak'anyengo M, Birungi H, Keesbury J, Askew I. 2012. Routine screening for intimate partner violence in public health care settings in Kenya: An assessment of acceptability. APHIA II OR Project in Kenya/ Population Council: Nairobi, Kenya.

8 Heise L, Ellsberg M, Gottemoeller M. 1999. Ending violence against women. Population Reports, Volume XXVII, No. 4, Series L, Number 11.
} 
enhancing access for survivors 9 ; through enhanced referrals; and by pinpointing the underlying cause of various health conditions, thus leading to more accurate diagnoses. These activities, however, may only be valid in health care settings where health providers have the capacity to offer basic support at the first point of contact with survivors, where referral systems and linkages are operational, and where referrals can competently be made to comprehensive services. Other barriers that call for a cautious approach to routine screening in developing countries are: limited resources to protect confidentiality; cultural and social barriers that may lead to patient non-disclosure; and the potential risks and unintended consequences for screened survivors whose follow-up care is inadequate.

Many of these potential barriers are presumed, however, and have not been fully tested in health care settings in developing countries. This study tested the feasibility of implementing IPV screening protocols in health care settings where SGBV service referrals could be executed.

9 Bott, S., Guedes, A., Claramunt M.C. Güezmes,A. 2004. Improving the health sector response to Gender-Based Violence: A resource manual for health care managers in developing countries. New York: IPPF, Western Hemisphere Region (IPPF/WHR). 


\section{STUDY AIM AND DESIGN}

\section{Aim}

The study aimed to determine the feasibility of routine screening for intimate partner violence in Kenyan public health care settings.

\section{Design}

This study employed a descriptive case study design. Primarily qualitative in nature, the case studies used semi-structured, in-depth interviews (IDIs) with clients and focus group discussions (FGDs) with providers in four sites within Kenyatta National Hospital (KNH) in Nairobi, Kenya: the antenatal care clinic (ANC); the HIV comprehensive care centre (CCC); the GBV clinic, referred to as the 'Gender-Based Violence Recovery Centre' (GBVRC); and the youth clinic, referred to as the 'Youth Centre.' Each site was investigated as a separate 'case,' with service statistics used to supplement the qualitative data.

In addition to being the oldest and largest public referral, teaching, and research hospital in the East African region (with an annual outpatient attendance rate of 600,000 visits per year ${ }^{10}$ ), $\mathrm{KNH}$ has the capacity to execute SGBV referrals. Its GBV clinic (the GBVRC) offers comprehensive postrape care services and attends to other forms of violence, demonstrating strong potential to be able to support a routine IPV screening intervention.

The GBVRC is housed within the Mental Health Department of KNH, which also provides psychosocial support for specific groups (e.g., substance abuse clients, HIV-positive clients, and children with special needs). Specific days of the week are allocated to caring for some of these special groups (e.g., children, substance abuse clients, etc.), with staff of the Mental Health Department responsible for providing services for SGBV clients and other clients that present at the Department.

10 Mars Group. 2007. The Kenyatta National Hospital. http://www.marsgroupkenya.org/pdfs/Oct 07/Parastatals/Kenyatta_National_Hospital/THE KENYATTA NATIONAL H OSPITAL Mandate.pdf. 


\section{INTERVENTION DESCRIPTION}

The intervention involved three main activities:

1. Provider training to screen for IPV routinely (April to May 2012);

2. Routine screening for IPV by providers (over a seven-month period: June to December 2012); and

3. Provider referral of IPV-positive clients identified through screening to the GBV clinic for further care (over a seven-month period: June to December 2012).

\section{Provider training to screen for IPV}

In collaboration with the GBVRC, the Population Council trained a total of 121 providers to screen for IPV. They were mainly drawn from the ANC, CCC, GBVRC, and Youth Centre, but also included representatives from the Health Information Systems Department (Medical Records), given the important role of service statistics in evaluating the intervention. The providers drawn from the four main departments represented a range of cadres, including medical records staff, receptionists, nurse counselors, HIV and/or youth counselors, psychologists, psychiatrists, incharges, deputy in-charges, client advocates, and heads of department. Several of these providers also functioned as trainers in their respective departments and were deliberately selected to ensure that the project built the capacity of KNH trainers to pass on SGBV training to others. Providers were trained in six separate groups of approximately 20 participants each over a six-week period. Each group was composed of providers from each key department (ANC, CCC, GBVRC, and Youth Centre).

The training sessions were designed to be one-day long (see Appendix 1 for training schedule). The structure and content of the training sessions were adapted from a publication entitled Improving the Health Care Response to Domestic Violence: A Trainer's Manual for Health Care Providers. ${ }^{11}$ The values clarification element of the training sessions was adapted from Researching Violence Against Women: A Practical Guide for Researchers and Activists. ${ }^{12}$

These highly interactive and participatory training sessions involved a variety of components, including: an introduction to the study goals; defining IPV and outlining justifications for IPV screening; values clarification exercises around SGBV in general and IPV in particular; the psychology of a survivor of IPV; focused exercises on IPV screening, documentation, and referral; and refinement of the screening questions and referral processes based on provider input and feedback. The training sessions were also used as a platform for providers to proactively map out exactly how IPV screening and referral would play out in individual departments.

\footnotetext{
11 Ganley, A.L. et al. 1998. Improving the Health Care Response to Domestic Violence: A Trainer's Manual for Health Care Providers. The Family Violence Prevention Fund: San Francisco, CA.

<http://www.futureswithoutviolence.org/userfiles/file/Maternal_Health/HealthTrainerManual.pdf>.

12 Ellsberg, M. and Heise, L. 2005. Researching Violence Against Women: A Practical Guide for Researchers and Activists. Washington DC, United States: World Health Organization, PATH < http://whqlibdoc.who.int/publications/2005/9241546476 eng.pdf>.
} 


\section{Routine screening for IPV by providers}

Subsequent to the training sessions, providers began the IPV screening exercise, focusing on asking every female client aged 18 and above attending services in the ANC, CCC and Youth Centre three questions to identify current experiences of physical, psychological, and/or sexual forms of IPV (see Appendix 2 for screening form). Providers were trained to preface the actual screening with a brief introduction explaining why these questions were now routinely asked at the clinic concerned. Clients whose records indicated that they had already been identified as IPV-positive were not to be asked the screening questions again. Those that had been screened but were recorded as being IPV-negative, were to be asked the questions at each subsequent visit.

The availability of IPV screening forms was monitored by medical records staff in the ANC, CCC, and Youth Centre, and replenished by the Population Council as needed. Medical records officers also ensured that the screening form was placed in clients' files in advance to help facilitate screening. Reminders in the form of posters were strategically placed in each screening location to help providers remember to screen for IPV. The posters asked the unobtrusive questions, 'Have you asked? Have you recorded?'

Each department was provided with an IPV registry/record book to document information on clients that had been identified and referred to the GBV clinic. To incentivize participating staff, each provider involved in the screening exercise received a stipend of Kshs 500 (about USD 6) per day for each day that they were on duty within the duration of the screening exercise.

\section{Provider referral of IPV-positive clients to the GBV clinic for further care}

Clients that answered 'yes' to one or more of the screening questions were considered IPVpositive and were referred to the GBVRC using a referral slip. In addition, whenever possible, referrals either involved telephone communication between the initiating and receiving departments to request for a client advocate to escort the client to the GBVRC; the provider walking the client down to the GBVRC him/herself; or an auxiliary staff member acting as an escort from the referring department to the GBVRC. The intervention covered the costs of a stipend for one client advocate to be available to escort clients during GBVRC opening hours.

Although basic services related to sexual violence are free at public GBV clinics in Kenya, care for other forms of violence incur a cost. To address this potential barrier, the study covered the following costs for survivors of physical and/or psychological IPV identified as a result of the screening exercise: 1) the cost of opening up a new patient file at the GBVRC, and 2) the cost of the first consultation/counseling session at the GBVRC. 


\section{Screening for IPV: Practical issues for consideration}

The planning sessions with providers addressed practical issues that required careful consideration to enhance the IPV screening process. These sessions helped providers in each department to think through critical questions and essentially design their own unique response to IPV. The following critical questions emerged and were resolved by participants during the provider training sessions:

\section{Who should do the screening?}

Providers in the ANC decided that nurses were best-placed to screen for IPV in their setting, while in the CCC and Youth Centre, screening was handled by counselors (including HIV- and nursecounselors). In the CCC, the screening process was overseen by the psychologist, who also participated in screening clients.

\section{Where should the screening be done?}

Providers identified the best locations for IPV screening to occur in their individual departments, given the ethical issues of privacy and confidentiality. The identification process was straightforward for the CCC and Youth Centre departments, which have a lower client load and several private rooms. Consequently, within these settings, care is only ever administered to clients in the privacy of a room. In the ANC, however, this issue required more careful consideration. Providers in this department came to the conclusion that ANC clients could be assured of absolute confidentiality when they presented for HIV pre- and post-test counseling sessions. These sessions occurred in the privacy of a room, and meant that routine screening in the ANC was limited to clients presenting for this kind of counseling.

\section{When should clients be screened (i.e., How routine is 'routine'?)?}

Various time points offer an opportunity to screen for IPV, depending on the clinic concerned. Critical screening opportunities exist, for example, at every client visit, in every new trimester (for pregnant women), at every new patient visit, in the course of every new intimate relationship, or at every episodic visit. ${ }^{13}$ ANC providers settled on screening clients specifically at every HIV preor post-counseling visit (which involves clients attending for their initial ANC visit), while providers in the CCC and Youth Centre decided to screen at every client visit. In all cases, clients already identified as IPV-positive on the screening forms were not screened a second time.

Given that ANC and CCC clinics encourage women to present at the hospital with their partners, providers used the planning sessions to consider the ethical issues that IPV screening would pose in their departments. Despite these important efforts to involve men in the health of their female partners, CCC providers pointed out that providing separate services to members of a couple was not unusual in their service delivery practices (e.g., when collecting baseline information for a couple that presents at the Comprehensive Care Centre). The unequivocal conclusion was that IPV screening would only ever occur in complete privacy, and that screening should be avoided if separating women from their partners ever proved problematic.

13 The National Consensus Guidelines on Identifying and Responding to Domestic Violence Victimization in Health Care Settings. The Family Violence Prevention Fund. September 2002 www.endabuse.org. 


\section{What timing of violence is of interest?}

To simplify the screening process, the study focused on screening for client's current experience of IPV. Delineating the timing of violence turned out to be important as the screening questions could (and did) occasionally prompt a 'yes' response for clients that had experienced IPV in the distant and recent past. Funding considerations led to a decision to identify only clients with current experiences of IPV for further SGBV care. Clients with past IPV experiences who were discovered as a result of the screening exercise were still referred to the GBVRC, however.

\section{Which type of violence should be screened for?}

Previous investigations of IPV in Kenya suggest that women conceptualize violence as a complex phenomenon with a variety of manifestations, including economic, physical, psychological, and sexual. ${ }^{14}$ The current intervention, however, sought to screen only for forms of violence that could be adequately attended to at the GBVRC. For this reason, providers agreed that screening for economic violence should not form a part of the intervention, but were emphatic about the need to screen for psychological violence in particular, in addition to physical and sexual violence. The study was able to accommodate screening for psychological IPV as the GBVRC is well-staffed with a team of psychiatrists, psychologists, and nurse counselors. To cater for IPV-positive clients that presented with an experience of physical violence, the intervention covered the cost of initial consultations at the GBVRC for these clients. Sexual violence was already a covered service at the GBVRC.

14 Undie C., Maternowska CM, Mak'anyengo M, Birungi H, Keesbury J, Askew I. 2012. Routine screening for intimate partner violence in public health care settings in Kenya: An assessment of acceptability. APHIA II OR Project in Kenya/ Population Council: Nairobi, Kenya. 


\section{DATA COLLECTION}

The three sites (ANC, CCC, Youth Centre) were selected through a theory-driven sampling strategy, ${ }^{15}$ relying on theoretical knowledge to determine eligibility for participation or selection. As violence has been shown to be experienced by a considerable proportion of pregnant women, HIV-positive women, and young people, sites that cater to these specific populations were considered appropriate for participation in this study. Given that these sites referred IPV-positive clients to the GBVRC for further care, data were also collected from the GBVRC as the receiving facility.

The study instruments included discussion guides for IDIs with clients and FGDs with providers (see Appendix 3 for study tools). The two guides for IDIs with clients were translated into the local language (Kiswahili) and pre-tested. Adjustments informed by this exercise were made subsequently. Two research assistants received training on the goals of this feasibility phase of the project, the content of the tools, data collection, ethics, and verbatim hand-recording of interviews over a five-day period. Although these were the same research assistants responsible for data collection under the acceptability study phase of the overall project, ${ }^{16}$ sensitization on sexual and gender-based violence still formed a core part of the training.

The study received ethical and research clearance from the Institutional Review Board of the Population Council, the KNH/University of Nairobi Ethics and Research Committee, the National Ethical Review Committee of the Kenya Medical Research Institute, and the Kenya National Council for Science and Technology. Individual, written informed consent was obtained from all participants before conducting the interviews and discussions.

Data collection took place from June to December, 2012 and included semi-structured, in-depth interviews with clients in the ANC, CCC, and Youth Centre; focus group discussions with providers in the ANC, CCC, GBVRC, and Youth Centre; and the collation of service statistics from all departments.

For the purposes of the study, clients were categorized as 'compliant' if they were screened, identified as IPV-positive, and successfully referred to the GBV clinic. They were categorized as 'non-compliant' if they were screened, identified as IPV-positive, and unsuccessfully referred to the GBV clinic. A total of 36 'compliant' clients and 29 'non-compliant' clients were interviewed, while a total of 23 providers participated in the FGDs.

To be eligible for study participation, clients had to satisfy the following criteria:

- Female, aged 18 and above, who sought services at one of the three study sites; and

$\circ$ Went through IPV screening with a trained provider, was identified as IPV-positive and referred to the GBV clinic.

15 Miles, M.B. and Huberman, A.M. 1994. Qualitative Data Analysis: An Expanded Sourcebook. Thousand Oaks, CA: Sage.

16 See Undie C., Maternowska CM, Mak’anyengo M, Birungi H, Keesbury J, Askew I. 2012. Routine screening for intimate partner violence in public health care settings in Kenya: An assessment of acceptability. APHIA II OR Project in Kenya/ Population Council: Nairobi, Kenya. 
Providers were eligible to participate in the FGDs if they had participated in screening clients for IPV at the ANC, CCC, or Youth Centre, or if they provided IPV care at the GBVRC.

\section{In-depth Interviews}

Short, semi-structured in-depth interviews helped to assess the feasibility of routine screening for IPV from the perspective of screened clients. The IDIs explored the following issues: perceptions and feelings after being asked questions related to IPV by a provider, the acceptability of routine screening, clients' experience with the referral process, perspectives about the quality of care and support received at the first point of contact and at the GBV clinic, suggestions for improvement and recommendations, and - in the case of 'non-compliant' clients only - barriers to referral follow-through.

'Compliant' and 'non-compliant' clients alike were screened by a trained psychologist within the GBVRC for their psychological readiness to participate in the study. If psychological readiness and willingness to participate in the study were established, clients were referred to a trained research assistant for an interview. Clients were categorized as 'non-compliant' if they had not presented at the GBVRC one month or more after referral. In these cases, the psychologist would follow up with 'non-compliant' clients by phone, using a phone script (see Appendix 4), to introduce the study to them. The phone script was used to ensure confidentiality and safety for the survivor, and the psychologist was trained to use it appropriately. Those interested in study participation were screened in person for psychological readiness at a later date, and referred to a research assistant for an IDI, if appropriate.

\section{Focus Group Discussions}

FGDs with providers sought to unearth the provider perspective on the feasibility of IPV screening. Specifically, these discussions at the ANC, CCC, GBVRC, and Youth Centre centered on perceptions of how the screening protocols were working, including ease of use, time, and comfort with the screening questions; suggestions for adjustments to the screening questions or screening/referral process; and experiences in asking IPV screening questions, and in handling clients that disclosed IPV. One FGD was conducted per site, for a total of 4 FGDs. Twenty-three providers across the ANC, CCC, GBVRC, and Youth Centre participated in these FGDs.

\section{Service Statistics}

Service statistics were abstracted from June to December 2012 to determine trends in the profile of survivors identified, and the number of referrals issued and completed. The service statistics were collated by research assistants via a review of the IPV registry/record book in each department. 


\section{DATA PROCESSING AND ANALYSIS}

Trained research assistants hand-recorded the in-depth interviews verbatim, typing up the handrecorded interview transcripts in MSWord at the end of each day of fieldwork. Focus group discussions were conducted by a principal investigator. They involved an average of 6 participants each and were audiotaped as hand-recording was impractical with this number of respondents. The audiotaped FGDs were later transcribed in MSWord.

Data analysis relied mainly on content analysis techniques, with each principal area of inquiry serving as a thematic code. However, emerging issues that were unanticipated, yet relevant for assessing feasibility, were included in the analysis and served as thematic codes as well.

In the first phase of analysis, data from each participating department were examined to understand individual departments as separate 'cases,' independent from the other participating clinics. This 'within-case analysis' 17 permitted an understanding of the unique experiences of each department. The second phase of analysis involved comparing principal themes across all study sites and respondent groups (i.e., 'compliant' clients, 'non-compliant' clients, and providers). This phase of 'cross-case analysis' 18 helped assure attention to confirming and disconfirming evidence, thus facilitating arrival at reasonable conclusions about the intervention.

17 Miles, M.B. and Huberman, A.M. 1994. Qualitative Data Analysis: An Expanded Sourcebook. Thousand Oaks, CA: Sage.

18 Ibid. 


\section{KEY FINDINGS}

\section{Clients were willing to disclose IPV}

The feasibility of IPV screening and referral is closely tied to clients' willingness to report IPV in the first place, particularly

\begin{tabular}{|l|l|l|l|}
\hline \multicolumn{4}{|c|}{ Table 1: Service Statistics for Initiating Departments* Combined } \\
\hline $\begin{array}{l}\text { Total \# screened } \\
\text { and documented }\end{array}$ & $\begin{array}{l}\text { Total \# } \\
\text { reporting IPV }\end{array}$ & $\begin{array}{l}\text { Total \# referred } \\
\text { to GBVRC }\end{array}$ & $\begin{array}{l}\text { Total \# presenting } \\
\text { at GBVRC }\end{array}$ \\
\hline 1210 & 95 & 73 & 29 \\
\hline *ANC, CCC, and Youth Centre &
\end{tabular}
given socio-cultural barriers that could prevent disclosure. Study results indicate that $8 \%(n=95)$ of all clients screened $(n=1210)$ reported experiencing some form of IPV currently (Table 1$).$ Psychological violence was the most commonly-reported form of violence overall (Table 2), followed by sexual violence, and, lastly, physical violence. Although sexual violence was the second most commonly-reported form of IPV, it is noteworthy that this type of violence only featured prominently in the reports of clients screened at the Youth Centre in particular, while clients screened at other points were more likely to cite physical violence than sexual violence. Also of note is the fact that the majority of women identified as being IPV-positive were experiencing more than one type of IPV simultaneously.

\begin{tabular}{|l|l|l|l|l|}
\hline \multirow{2}{*}{ Table 2: Types of IPV reported by clients } \\
\hline Department & Total \# & \multicolumn{4}{l|}{ Types of IPV reported } \\
\cline { 3 - 5 } & reporting IPV & physical & psychological & sexual \\
\hline ANC & 26 & 17 & 18 & 10 \\
\hline CCC & 13 & 12 & 12 & 10 \\
\hline Youth Centre & 56 & 20 & 38 & 37 \\
\hline
\end{tabular}

Qualitative evidence indicates that although some providers were initially doubtful about the possibility of clients disclosing IPV, they soon discovered that screening clients specifically for this condition could lead to disclosure:

[W] hen we started, we thought that we [could] not get anybody who can be that open [to say], 'I am being beaten,' but ... we are getting clients. Yeah, and we thought when we were starting - me, I thought we cannot get any person like that (FGD with Providers, ANC).

In fact, one [client] asked why we hadn't asked those questions earlier because she has passed through a lot, and from ... the questions, at least she has been able to now see a way [forward]. .... Yeah, she was actually feeling that she [should] have been asked 'yesterday' (FGD with Providers, CCC).

We are finding them [clients] asking many questions: 'Why did we ask those 3 questions and not more? .... Why only 3?' [Clients feel] that we are very brief (FGD with Providers, ANC).

Over a third (38\%) of IPV-positive clients identified by providers through screening were youth aged between 18 and 24 years. This is disproportionately high, given that young people in this age range made up a mere $3 \%(n=33)$ of the total number of clients screened and documented by providers. 


\section{Providers demonstrated capacity to screen for IPV and provide referrals for}

\section{further care}

Over the life of the intervention, providers across all referring departments screened a total of 1,210 clients without the emergence of adverse events for those screened (Table 1). Of those that reported being IPV-positive ( $n=95)$, providers referred $73(77 \%)$ for further care at the GBVRC (Table 1). Women screened at the CCC were the most likely to be positively screened for IPV (24\%), followed by women screened at the Youth Centre (17\%), and those screened at the ANC (3\%) (Table 3).

\begin{tabular}{|c|c|c|}
\hline Department & Total \# screened & Total \# reporting IPV \\
\hline ANC & 826 & 26 \\
\hline $\mathrm{CCC}$ & 55 & 13 \\
\hline Youth Centre & 329 & 56 \\
\hline Totals & 1210 & 95 \\
\hline
\end{tabular}

Providers largely felt comfortable asking the screening questions, were of the opinion that doing so did not take an inordinate amount of time, and felt that the exercise was important:

For me also, it doesn't take a long time. Between 4-5 minutes, we should be done with the screening; and about comfort: I'm very comfortable with asking the questions because, out of the training, I realized it was an empowerment to be able to reach some souls that ... do not know anything about where they can turn in terms of help (FGD with Providers, Youth Centre).

Since the ANC services are wide, we usually inform [clients] that there are other services that we give apart from caring for you and the baby .... So really, it is like part of our training that we undergo as nurses. We are also trained on holistic care of the patient .... So we really don't find [screening for IPV] ... difficult (FGD with Providers, ANC).

It would be important for screening actually to happen maybe at all entry points because we have realized that ... the health issues that bring people to the clinic are related to some IPV, and ... so for us to cut down on these people coming to the hospital ... (FGD with Providers, CCC).

Clients' narratives (both 'compliant' and 'non-compliant' clients) demonstrated a similar degree of comfort, with respondents overwhelmingly indicating their appreciation of the brevity, clarity, directness, and usefulness of the screening questions:

The questions should not be changed because they were short, simple, and clear (IDI, 'compliant' client, Youth Centre).

I was happy because there was no one - not even in my family - who had ever asked me such questions before. But I was ready to talk about it because it was like a burden inside me which I wanted to remove. It is painful to know that you have been infected by someone and yet you had really taken care of yourself by being faithful. It was painful, but I just decided to talk about it (IDI, 'non-compliant' client, CCC).

They were okay, those questions I was asked. I had never been asked by anyone before. And the way they were asked - they were a bit educative. ... I had never thought about it like that before. I used to think [IPV] is just normal, but I had never linked it to being abused or to my health (IDI, 'compliant' client, ANC). 
I was very comfortable because I didn't have anyone else to talk to. So I opened up my heart and I felt like that burden in my heart had gone. I was going through some personal things at the time. I had come to Kenyatta with my cousin to see a relative of ours who had been burnt by fire. We were told that we had come early so we were told to wait for the visiting hours. And since we had nowhere else to go while waiting, we decided to go to the [Youth Centre] and get tested [for HIV], which is something which I had never done before. So that lady there talked to me nicely and I felt that maybe God had sent me there to find someone I can talk to (IDI, 'non-compliant' client, Youth Centre).

Indeed, all clients interviewed (regardless of compliancy status) regarded IPV screening as an important and useful undertaking.

\section{Some providers innovated with the screening process, however}

An analysis of the qualitative data revealed that, despite focused training on how to screen clients for IPV as part of the intervention, some providers in the ANC devised IPV screening methods of their own. Specifically, there were some ANC providers who gave clients the IPV screening form to fill out independently, rather than ask the clients the screening questions themselves. Clients' accounts suggest that some providers may simply have viewed this method as more convenient, given the large client load at the ANC, compared to other study sites.

Although screening women through self-completion of the screening form was not the design of the intervention, interviews with 'non-compliant' and 'compliant' clients at the ANC suggest that it did not significantly hamper the likelihood of IPV identification. Likewise, the success of referrals did not seem to have been hindered by this practice. A few ANC clients specifically mentioned not being asked the IPV screening questions by a provider:

But for me, I wasn't asked. I read them for myself .... I was wondering why they are asking personal questions, but I thought that maybe they have some help that they are providing, so I did not mind answering them. ... They [the screening questions] were private. I mean that I was given a form to fill for myself. So it is up to you to decide whether to answer them or not. If they were to ask me, it would not have been private because I would not have been on my own while answering. I would also be with the person asking me the questions. But at least I was reading them for myself, so it was okay. There was also no one else around on that table when I was filling [the IPV screening form] (IDI, 'compliant' client, ANC).

I did not talk with anyone. ... We were told that there is a form in the file that we have to fill. Then after going through the services, we were being called in a room one by one, then you fill the form alone. Then when I finished, I gave it back and then I was given [an escort] and I was brought here [GBVRC] (IDI, 'compliant' client, ANC).

These clients were 'compliant,' however, suggesting that the approach of some ANC providers, while not encouraged by the intervention, was not detrimental to some clients' ability to receive care.

On the other hand, while 'non-compliant' clients at the ANC largely expressed satisfaction with the questions, 3 clients in this category did not understand them, and attributed this to having to read the questions on their own, rather than having a provider ask the questions. As they explained:

The nurse called me and told me that 'There are questions in there [the file]. I want you to read them and answer them.' When I read, I understood the questions to 
[refer to] any relationship - even outside marriage, and I answered 'yes' because there is someone who I am related to who treats me badly. Because my husband does not treat me badly; I don't have any problem with him. .... I did not know that they were supposed to be about inside the marriage, and there was no one around whom I could have asked. [wasn't IPV positive]

I did not understand the questions. I was just given a paper to fill. I wanted to ask a nurse to explain for me what I was supposed to do. The nurse who had given me the file had gone somewhere else. I tried to call another nurse to ask her a question, but there were so many people and she was busy ... then I decided to fill it myself. [was not referred, but did come to GBVRC after a follow-up call]

I was not asked the questions by a provider, but I was given a form which had the questions to fill in. Though I did not understand so much what the questions were about, I just filled in the questions[.] [was admitted into the hospital for delivery]

Of these 3 clients, 2 turned out to be IPV-positive. One could not be referred as she was admitted for emergency care on the day of screening, and the other was not referred by the provider. She did receive care at the GBVRC on a later date, however, after receiving a follow-up call from the psychologist under the project.

\section{Male involvement had implications for the screening process}

Discussions with providers revealed an interesting dynamic in the ANC and CCC departments in particular. ANC providers observed that, increasingly, clients in this department are encouraged to attend the clinic along with their partners. Given this effort to encourage male participation in the ANC, providers would sometimes have to refrain from screening clients for IPV.

We are finding some challenges, especially when a [client] is accompanied by the spouse .... So ... we don't fill that [screening] form when the spouse is there, but we note somewhere that [the] matter is not accomplished; we shall accomplish [it] later (FGD with Providers, ANC).

In the CCC, on the other hand, providers observed that many of their clients were not (or were no longer) in union (due to death, divorce, separation, etc.), making the screening questions relevant for only a certain proportion of CCC clients:

We actually receive very many female patients, but upon interview, when we maybe ask about their partners or whether they have spouses, actually, majority of the female patients are always saying that they are not together; they are separated. ... I mean, I know a lot of violence [goes] on in relationships, but sometimes ... they are no longer in relationships because maybe they were both ill and one has passed away, or they have separated because of the violence, or because of the discovering of the [HIV] status and all that ... (FGD with Providers, CCC).

\section{Referral systems and linkages were found to be largely operational}

To facilitate the referral process, initiating departments worked closely with the GBVRC, using phone calls to alert the GBVRC of IPV-positive clients. In turn, the GBVRC would send a client advocate to the initiating department who would escort the client to the GBVRC and assist them in navigating any administrative processes. In cases where auxiliary staff were available (e.g., peer mentors, janitors, messengers, students in training), they also occasionally walked clients down to the GBVRC. Providers themselves also played this role personally, if time permitted. This 
practice was encouraged to ensure that clients arrived at the referral destination via what is a complex pathway from some clinics where screening occurred.

[My husband] told me it was my fault [for going] to the hospital late and therefore he won't give me any money to go back to the hospital. I felt so stressed that I gained courage and went to one of the nursing officers in charge and told her about my challenges. When she heard my story, she took me to one of the providers to assist me and make sure I get the services required. When we went in a room ... she asked me if I was experiencing any form of violence, and when I said 'yes,' she told me that she would refer me to the GBVRC. She then called a lady who came and picked me [up] and we then came with her here [GBVRC] (IDI, 'compliant' client, ANC).

Except for two clients referred from the CCC, all 'compliant' clients across the three initiating departments were escorted from the department concerned to the GBVRC. The two compliant clients that did not have an escort were provided with directions, and, given the close proximity of the CCC to the GBVRC neither had any problems locating the GBVRC. One client that did receive services after being escorted to the GBVRC stressed the importance of the client advocate's role:

Kenyatta [National Hospital] is vast. It is difficult to come alone with no one to bring you. If you are alone, you can get nervous while on the way ... you can lose your nerve. You can get lost; you can change your mind and decide not to come. But if you are walking with someone, there is that support you get because of walking with that person ... you feel comfortable going (IDI, 'compliant' client, CCC).

Although the initial intention under the intervention was for IPV-positive clients to receive sameday services at the GBVRC, this was not always possible. For several reasons (enumerated later in this report), women felt pressed for time - or GBVRC staff were not always immediately available. Occasionally, clients preferred to have their initial GBVRC appointment on a later date. When this occurred, appointments were scheduled on later dates for the clients concerned.

When I came here [GBVRC], I met a lady ... and she told me that she had called [the GBVRC] and the person who was supposed to see me was not in. She told me that I should come back on Monday. ... So I just had to come back on Monday, which is today (IDI, 'compliant' client, ANC).

They told me that since you have answered 'yes' to these questions, we would like you to go to the [GBVRC] to get a counseling session on what you have been going through to help you cope with it. I was told that they will have someone come for me and bring me[.] When we came on that day ... I had to go for my specs [eye glasses] in town and so I was told that I can come back again when I have time. So I came back today (IDI, 'compliant' client, CCC).

Knowing my [HIV] status is what I was really interested in. I had been tested and since I was negative, I was wondering about where else I was being taken. Then [the provider] told me that 'Because of what we talked about earlier, I will take you to another [provider]. She is the one who brought me here. That [provider] was not here, so I was booked to come back today (IDI, 'compliant' client, Youth Centre).

\section{Resources to protect confidentiality were found to be adequate}

The vast majority of clients were satisfied with the level of confidentiality that the screening and referral process involved. When asked about how happy they would say they were with the kind of care and support they received at the GBVRC, 'compliant' client interviewees often cited the confidentiality of the services as contributing to their satisfaction: 
The setting is okay. There was a lot of privacy and I could express myself without interruptions from other people coming in (IDI, 'compliant' client, ANC).

The setting is good since there are many rooms, which means there's privacy, which is an important factor (IDI, 'compliant' client, CCC).

[T]here's a lot of privacy since this place is hidden from where many people seek medical attention. No one can therefore suspect one to have gone to the GBVRC because some women may fear coming here because of the name (IDI, 'compliant' client, Youth Centre).

However, a few 'compliant' clients interviewed (2 out of the 36 ) expressed concerns about the lack of confidentiality, in their own experience:

When we were sitting on those benches [in the reception area], everyone was being asked why they had come. So, some girl was being asked why she came and she said she was raped. She was asked, 'Do you have any papers?' She said, 'No.' So, you see, other people could hear. I think if you are the one being asked like that and other people can hear what you are saying ... I think you [won't] come back here again (IDI, 'compliant' client, CCC).

The receptionist asked me some of those questions loudly. I told him to be soft because, 'Some of these things are too personal and I don't want other people to hear.' I told him to ask me softly like the counselor who had talked to me. He said that he is not a counselor (IDI, 'compliant' client, Youth Centre).

It is noteworthy that both cases occurred at either at the reception or waiting area of the GBVRC. Frontline providers were recognized as a key component of the intervention; thus, receptionists participated in the provider training sessions. During the intervention period, however, hospitalmandated staff transfers meant that these key positions were not always occupied by personnel trained in SGBV.

\section{Client satisfaction with IPV services was high}

The clients that did seek care at the GBVRC following referral were extremely satisfied with the services they received. The majority of these clients intended to return to the GBVRC for further counseling, with some having already set up follow-up appointments. Many planned to return to the GBVRC specifically to participate in support group sessions for GBV survivors. A few planned to return with their children, realizing that they could also benefit from the psychosocial support services offered at the GBVRC.

I am happy. The first person I talked to was free and was ready to listen. She gave me time - like for crying. I cried and she gave me time to cry. Then she also gave me advice on what to do. She is also friendly and understanding. Just the way that she was talking ... she is open-minded and you don't fear her. She also makes you to be open-minded and she makes you to talk, even if you don't feel like talking. She was just understanding ... I don't know how to explain it, but she was just understanding (IDI, 'compliant' client, ANC).

There are some things which you keep to yourself and you never tell anyone. When you get someone to talk to about those things ... things which have been deep inside you ... when you talk about them ... I think it just relieves you. I'm feeling relieved. The staff looked concerned. When we were sitting at the reception, someone was coming to ask us if we had been assisted. They wanted to assure us that something was being done to help us (IDI, 'compliant' client, CCC). 
I am happy. I was able to sleep nicely for the first time in a long time. I slept at ten and woke up at five. I can't remember the last time I was able to sleep that nicely. ... It is because of the counseling I got here yesterday. I was happy ... it was excellent (IDI, 'compliant' client, Youth Centre).

\section{Although referrals were happening, referral uptake was relatively low}

Although the majority of IPV-positive clients identified by providers were referred to the GBVRC (77\%), a review of the service statistics indicates that only $40 \%$ of those reporting IPV in the ANC, CCC, and Youth Centre combined (29 out of 73), presented at the GBVRC for further care after the first referral (Table 4).

\begin{tabular}{|l|l|l|l|l|}
\hline \multicolumn{5}{|c|}{ Table 4: Service Statistics for Individual Departments (June to December 2012) } \\
\hline Department & Total \# screened & $\begin{array}{l}\text { Total \# reporting } \\
\text { IPV }\end{array}$ & $\begin{array}{l}\text { referred to } \\
\text { GBVRC }\end{array}$ & $\begin{array}{l}\text { received services } \\
\text { at GBVRC }\end{array}$ \\
\hline ANC & 826 & 26 & 12 & 5 \\
\hline CCC & 55 & 13 & 11 & 4 \\
\hline Youth Centre & 329 & 56 & 50 & 20 \\
\hline Totals & $\mathbf{1 2 1 0}$ & $\mathbf{9 5}$ & $\mathbf{7 3}$ & $\mathbf{2 9}$ \\
\hline
\end{tabular}

\section{Most clients were willing to comply with referrals for SGBV care}

Triangulation of the service statistics with the qualitative data lends some insight into these comparatively lower referral uptake rates. Firstly, the in-depth interview data demonstrate that out of all the 'non-compliant' clients that could be reached telephonically for interview, none were actually 'non-compliant' because their reasons for non-compliance were largely related to health systems barriers to effective referral, rather than to any personal disinclination on their part (Table 5). While these findings confirm the high acceptability of IPV screening among clients, they also point to areas of the intervention that can be strengthened - notably, provider referral reminders and the structuring of service provision at GBV clinics.

\begin{tabular}{|c|c|}
\hline Reason & \# of clients citing reason \\
\hline $\begin{array}{l}\text { time constraints } \\
\text { (client had to be elsewhere) }\end{array}$ & IIIII III \\
\hline provider did not refer & IIIII II \\
\hline GBVRC staff unavailable & IIIII I \\
\hline $\begin{array}{l}\text { referral process interrupted } \\
\text { (client had to be admitted on emergency basis) }\end{array}$ & III \\
\hline $\begin{array}{l}\text { provider meant to refer when client was done } \\
\text { with services, but could not be found by client } \\
\text { for referral }\end{array}$ & II \\
\hline client advocate/escort unavailable & II \\
\hline $\begin{array}{l}\text { client misunderstood screening questions (was } \\
\text { not actually IPV+) }\end{array}$ & 1 \\
\hline
\end{tabular}




\section{Clients' personal time constraints are a barrier to referral uptake}

One important reason for 'non-compliance' with referrals had to do with clients' personal time constraints. Clients in general presented at $\mathrm{KNH}$ for specific services which they expected to receive within a certain time period. Understandably, therefore, some clients had other commitments that prevented them from seeking immediate care for IPV at the GBVRC:

I was in a hurry to go since I had closed my business and I wanted to do something. I had said I would come [to the GBVRC], but it wasn't until [the psychologist] called me that I remembered (IDI, 'non-compliant' client, ANC).

One of the reasons that made me end up not going to where I had been referred is because it was late by the time I was through with the services at the CCC, and after that, it has also been difficult to get time off from my work place (IDI, 'non-compliant' client, CCC).

I was told that I can choose any day on which to go to the place because we did not have time that day. ... I had come with my cousin and she goes to Egerton University and I go to KISU College. So she went back to college and I lost the morale to come back alone because we were supposed to come back together (IDI, 'non-compliant' client, Youth Centre).

\section{Non-referral of clients by providers is a barrier to referral uptake}

Some providers did not refer after screening and identifying an IPV-positive client. Evidence of this is found in some in-depth interviews with clients, and during periodic intervention monitoring visits. During the provider training sessions, providers were instructed and trained to screen and refer. Providers were also informed during these sessions that a psychologist would follow up with 'non-compliant' clients by phone. Some providers took this to mean that they were only expected to screen for IPV. This erroneous impression was corrected once discovered during monitoring visits, but not before it had its impact on some clients. A few IPV-positive clients discussed providers' probable intention to refer after screening, along with their inability to complete the process immediately:

I came to KNH for ANC services and when the counselor had finished counseling me, she told me to go and see a gynecologist and [that] when I finish with the gynecologist, I should go back to her so that she could direct me to where to go for further help. When I finished with the gynecologist, I looked for her, but couldn't find her; therefore, I decided to leave (IDI, 'non-compliant' client, ANC).

I was told that there are people who are doing research and they are based at the [GBVRC], and they will give you a call to tell you the way forward - [how] they can assist you. They didn't tell me to come here [GBVRC] (IDI, 'non-compliant' client, CCC).

[M]aybe he forgot, because he did not tell me that if I answered 'yes,' I was to go somewhere (IDI, 'non-compliant' client, Youth Centre). 


\section{GBV clinic staff availability is a barrier to referral uptake}

There were occasions when providers referred clients to the GBVRC and the clients initially complied with the referral, only to find that their needs could not be attended to due to the unavailability of staff at the GBVRC. A range of reasons explain this: the referral occurred on a outside the GBVRC working hours (e.g., on a weekend); it was a special clinic day at the GBVRC (e.g., the weekly 'Pediatric Day') when the Centre is busier than usual, and specific clients (e.g., children) are given priority over others; it was a staff meeting day, involving all GBVRC staff; or the referral occurred during lunch and tea breaks when staff may not be available:

I went to where I had been referred, and since it was already lunch time, the providers at the GBVRC were going for lunch; and since I was also feeling hungry and with a diabetic condition, I also decided to leave so that I could get to the house in good time for my sugar injection (IDI, 'non-compliant' client, ANC).

I came because she had promised that I was going to be seen on that day. But when I came ... I was told that I cannot be seen ... I don't know, because they were not there ... I don't know if they had gone to the wards or something ... I don't know where they were ... So, then I asked if I could come back on Monday and I was told that I cannot be seen on that day because it is the Children's Clinic day. Then I was given another date, but I was not able to come back (IDI, 'non-compliant' client, CCC).

When I told her that I was experiencing violence, she told me that she would refer me to the GBVRC for further health care. Since it was a Saturday, she asked me if I would be willing to go to the GBVRC the following Monday. I couldn't come on Monday because it is not easy for me to get time off during weekdays, and that is the reason why I could not come (IDI, 'non-compliant' client, Youth Centre). 


\section{CONCLUSIONS AND RECOMMENDATIONS}

This study assessed the feasibility of routine screening for IPV with a focus on issues such as client willingness to disclose IPV, provider capacity to identify IPV-positive clients and refer them for comprehensive services, the extent to which referral systems were operational, the extent to which resources existed to protect confidentiality, and the quality of follow-up care for survivors in terms of potential risks and unintended consequences.

Despite noted imperfections in the screening process, overall in regard to these issues, the study results indicate that routine screening for IPV is feasible. The training sessions conducted as part of the intervention provided an opportunity to educate providers about an area of reproductive health that they are generally not comfortable inquiring about or dealing with, and as a result helped break down some of the presumed barriers. Even so, some providers carried out screening without providing referrals; however the reasons for this were not explored from the perspective of providers in this study. Furthermore, while clients found the intervention acceptable, numerous reasons-largely system-related-would often prohibit follow-up. Generally, however, clients expressed a positive opinion about the referral service and, when time permitted and staff at the GBVRC were present, the experiences were positive.

These findings, when paired with findings from the previous acceptability study, ${ }^{19}$ confirm that screening is feasible for identifying clients at risk and is desired by most clients. Clinicians and counselors overall agreed to the process and incorporated it into their normal busy practices. Nonetheless, it is clear that a complete shift in clinical norms-i.e., both completing the screening process and issuing the referral-still needs to occur.

The study results show that, through routine screening, providers identified between $3 \%$ and $24 \%$ of clients as being IPV-positive. The lowest reporting rate by clients in this study was observed at the ANC, at 3\%. A recent review of clinical studies from Africa reports prevalence rates of $2 \%$ to $57 \%$ for IPV during pregnancy, with meta-analysis yielding an overall prevalence of $15 \% .{ }^{20}$ While this would suggest that the IPV detection rate by ANC providers in this study lies within the range of IPV prevalence rates among pregnant women in the region, it is important to emphasize that the current study aimed to determine the feasibility of routine IPV screening, rather than the effectiveness of the same. There are various factors that might have influenced ANC reporting rates in this study, including the fact that, of all the referring departments, the ANC was observed to be the busiest, with approximately 1,000 new clients per month, according to ANC provider estimates. In this crowded context, male involvement was also being encouraged, which might have limited privacy and, therefore, screening opportunities. These factors could plausibly have hampered the effectiveness of providers' screening, resulting in lower reporting rates.

Kenya, along with many of its neighboring countries in East Africa, grapples with what is now an endemic problem of violence against women and children. Preventing and responding to violence requires resources and commitment, both of which are often in short supply for a myriad of

\footnotetext{
19 Undie C., Maternowska CM, Mak'anyengo M, Birungi H, Keesbury J, Askew I. 2012. Routine screening for intimate partner violence in public health care settings in Kenya: An assessment of acceptability. APHIA II OR Project in Kenya/ Population Council: Nairobi, Kenya.

20 Shamu S, Abrahams N, Temmerman M, Musekiwa A, Zarowsky C. (2011). A systematic review of African studies on intimate partner violence against pregnant women:Prevalence and risk factors. PLoS One, 6(3):e17591.
} 
reasons entwined with the culture, economics and the politics of gender. What remains essential is that evidence is continually gathered for improved advocacy. National surveys and service statistics in Nairobi indicate that violence is a common problem and that there is a significant demand for services. This study demonstrates that providers, given the training, are willing and able to incorporate IPV screening into their practice - one that they perform in a severely resource-constrained context. Likewise, the findings indicate that incorporating screening to into client in-take forms in a variety of health care settings in a public hospital is not only acceptable to clients, but is welcomed as an opportunity to air grievances and trauma. These are initial and important findings and steps forward in the field of violence response and prevention work. Below, we present several recommendations for strengthening the screening process and expanding its integration in other health facilities.

1. Two populations-clients from the CCC and clients from the Youth Centre- reported IPV at the highest rates in this study. These are therefore important target populations. CCC clients were also more likely than their peers in other clinics to report experiencing all three forms of IPV at the same time. HIV Comprehensive Care Centers therefore need to be cognizant of their clients' higher risk potential for composite abuse, and the implications for the health of these clients. The fact that Youth Centre clients were more likely, at least in this study, to report sexual IPV in particular is significant as it is during these early relationships that behavioral patterns are established. We suggest that extra effort be made to screen adolescents in a variety of health service and other settings and that innovative ways of discussing violence (through edutainment, for instance) be considered as a supplement to patient education generally.

2. The location for screening must be fully private to ensure patient confidentiality. To this end, it is important that receptionists at GBV centers/clinics and others responsible for client in-take are trained and reminded of the need for discretion when asking clients for 'reason of visit'. Auxiliary staff can also benefit from training and form a critical part of overall screening interventions. If a norm shift that recognizes IPV as a violation of human rights is to occur, ensuring that all hospital employees understand what violence is and how best to respond to it is essential. Teaching confidentiality as part of this process is mandatory. Front line providers can determine the entire experience for a client at the facility and so it is mandatory that these issues be addressed when introducing the intervention. Likewise, finding innovative ways of screening women without detracting from the need to involve male partners and family members in women's care-seeking, is critical.

3. Staffing at the referral endpoint-GBV centers/clinics-must be acknowledged as absolutely essential to the process of IPV screening. GBV centers/clinics need to recognize the urgent nature of sexual, physical and psychological violations and therefore ensure that at least one staff member is always on duty at the clinic, at the very least during normal working hours. During the screening process, providers should also provide alternatives to the clients in the event that screening happens when the GBV clinic is closed. Reinforcing clinic hours (and alternate care sites such as emergency rooms) should be understood by all hospital staff, and especially in clinics where screening is conducted.

4. Although screening and referrals completed during a single visit to the hospital is the gold standard, this study demonstrates that later appointments can work and should be seen and incorporated as a useful alternative, especially if the health facility concerned has a designated staff member to conduct discreet follow-ups. 
5. Training and repeat training of providers and periodic monitoring useful. As departments often experience rapid turnover of staff, or periodic staff transfers, IPV screening training should be a regular part of a clinic's orientation. This is particularly appropriate for KNH as a national teaching hospital.

6. Our results show that not a single client enrolled in the study was actually 'noncompliant,' but in effect had a genuine reason for not completing through with the referral process. This is an extremely important finding and should provide impetus to health facility administrators to address systemic problems that limit IPV-positive clients' access to existing services. Possible alternatives for addressing this issue include training providers in departments where screening occurs to offer basic psychosocial support for IPV; or incorporating 'roaming' GBV clinic staff into the referral process - i.e., GBV clinic staff that move from one department to another, attending to IPV-positive clients right away in the departments where they are identified to avoid losing clients during the referral process.

7. More investigation needs to be done around screening protocols within departments where clients are encouraged to attend appointments with their partners (CCCs, ANCs, etc.). We recommend further research to investigate the opinions of men around IPV screening and until then suggest that women are provide the privacy and security they need to report violence.

8. Given the large proportion of clients from the Youth Centre that reported IPV, and findings from the region that repeatedly show experiences of violence in children's lives, we recommend research to test the acceptability and feasibility of screening children for violence. 


\title{
APPENDICES
}

\section{Appendix 1: Provider Training Schedule}

\section{DEVELOPING AN INTIMATE PARTNER VIOLENCE (IPV) SCREENING PROGRAM}

\section{AT KENYATTA NATIONAL HOSPITAL}

\author{
Training \& Planning Agenda ${ }^{21}$
}

\section{PART ONE}

I. Welcome and Introduction of Participants (9:00-9:30 am)

- 1 minute per participant. Each individual to state their name, department, and provide a 'coin memory.' An overview of what we want to achieve under this project, and how.

II. Dynamics of IPV (9:30-10:30 am)

O Through interactive exercises, an overview of IPV, including definition, dynamics, causes, why women stay, the impact of IPV on other household members, and so forth, will be provided. Provider values about IPV will also be unearthed, explored, and discussed.

i. Activity l: 'Traffic Light' exercise (values clarification activity)

ii. Activity II: 'Why doesn't she just leave?' (values clarification activity)

iii. Powerpoint Presentation and Discussion

III. Tea Break (10:30-10:45 am)

IV. Testimonial: A Survivor's Story (10:45-11:15 am)

- A survivor to present her real-life experiences with the health care system, including what the system could have had in place, or done differently, in order to better serve her needs.

\footnotetext{
21 The structure and content of the training sessions were adapted from the publication entitled, "Improving the Health Care Response to Domestic Violence: A Trainer's Manual for Health Care Providers," Produced by the Family Violence Prevention Fund. The primary author is Anne L. Ganley, Ph.D., with contributions by John Fazio, R.N, M.S., Ariella Hyman, J.D., Lisa James, M.A., and Anita Ruiz-Contreras, R.N., M.S.N, C.E.N. The values clarification exercises used during the training were adapted from the following publication: Ellsberg, M. and Heise, L. (2005). Researching Violence Against Women: A Practical Guide for Researchers and Activists. Washington DC, United States: World Health Organization, PATH.
} 


\section{PART TWO}

V. Clinical Skills: Screening, Documentation, and Referral (11:15 am-12:15 pm)

O The clinical skills health providers need to develop in order to work more effectively with IPV survivors, including screening, documentation, and referral, are to be addressed.

VI. The GBVRC as a Resource (12:15-12:30 pm)

O Introduction to the Gender-Based Violence Recovery Centre at Kenyatta National Hospital. Who are we at the GBVRC, and what are we here for? What do we do, exactly? What kind of care can clients expect to receive when they get here?

VII. Role Play and Discussion for Practical Application (12:30-1:00 pm)

O In groups of three, providers take turns to feel out the IPV screening questions. Each participant gets a chance to play the role of client, provider, and observer. Observations and experiences with this process are shared in plenary.

VIII. Lunch Break (1:00-1:45 pm)

IX. Group Work by Hospital Site: Developing an Action Plan (1:45-2:45)

- Providers from each hospital site will spend time developing (and then, reporting back on) an initial 'action plan' for implementing their department's response to IPV clients. Each action plan should address the following: identify obstacles, strengths and solutions in organizing your department's response to IPV; identify ways for providers in your department to begin working with the Gender-Based Violence Recovery Centre to meet the needs IPV survivors; identify additional staff recruits to the team from within your department (security, clergy, providers in training, volunteers, etc.); and assign specific responsibilities to yourselves and others in your department.

X. Closing Session (2:45-3:15 pm)

O Each participant to briefly highlight one thing that they will take away from the trainingplanning session, or to share any closing reflections they may have. Each participant to complete and submit a simple, anonymous evaluation form. 


\section{Appendix 2: IPV Screening Form}

\section{Kenyatta National Hospital (KNH) and Population Council \\ Screening Form for Intimate Partner Violence (IPV)}

IPV screening will be conducted by making the following statement and asking the 3 questions below:

Many people do not realize that violence can lead to all kinds of health problems. Because violence is so common in many women's lives, and because there is help available at $\mathrm{KNH}$ for women being abused, we now ask every patient at the ANC about their experiences with violence. Please be assured that your answers to these questions will be kept strictly confidential:

1. Are you currently in a relationship with a person who physically hurts you? Yes No

2. Are you currently in a relationship with a person who threatens, frightens, or insults you, or treats you badly? Yes No

3. Are you currently in a relationship with a person who forces you to participate in sexual activities that make you feel uncomfortable? Yes No

[Note to provider: If one or more 'yes' options are ticked, REFER client to the Gender-Based Violence Recovery Centre (GBVRC) using a referral slip, and indicate the date of the referral below.]

DATE OF REFERRAL: Month Day Year

[Once a referral has been given, do not ask this client these questions again]. 


\section{Client Interview Guide}

\section{Assessing the Feasibility of Screening for Intimate Partner Violence (IPV) in Public Health Care Settings in Kenya \\ Population Council}

\section{For clients that were successfully referred}

Thank you so much for meeting with me today. My name is [Name]. I work with the Population Council on a project that is trying to make sure that women who have had experiences with different kinds of violence (e.g., beating by husbands/boyfriends; rape; etc.) are able to get the health care and help that they need.

We are speaking to several women that were recently referred to the Gender-Based Violence Recovery Center (GBVRC) at Kenyatta National Hospital (KNH) to ask some quick questions that will help us improve women's experiences with being screened for experiences of violence at $\mathrm{KNH}$, as you were.

If you agree to speak with me, I will take about 15-20 minutes of your time, asking about your experiences with being screened for violence at the $\mathrm{KNH}$, and your recommendations for improving the screening process. Everything we talk about will be totally confidential. Your name will not appear on any of our reports. I will be taking down notes as we speak to be sure I do not miss any of the important information you share with me. If at any point you would like to stop, or if there are any questions you would rather not answer, that is fine - just let me know. Is there anything you'd like to ask me at this point?

1. During a recent visit to $\mathrm{KNH}$, a provider asked you some personal questions about experiences you may have had with different kinds of violence. How comfortable would you say you felt about having the provider ask you these kinds of questions? Kindly elaborate.

o Is there another way you would suggest that such questions be posed to women in the future? Kindly elaborate.

- What did you like about the questions you were asked around violence? Just to remind you, you were asked questions about different kinds of violence, such as physical and sexual violence, and also psychological violence (e.g., being threatened, insulted, etc.).

o What did you dislike about the questions you were asked around violence?

2. How important do you think it is for women to be asked such questions regularly when they go to the hospital? Kindly elaborate.

3. After you answered the questions on violence, you were referred to the GBVRC here at KNH for further health care. Kindly walk me step-by-step through your experiences, describing how you were referred and how you got to the GBVRC.

- How happy would you say you were with the kind of care and support you received when you went to the GBVRC? Kindly elaborate. [probe on perceptions of the staff and the setting]

- Do you plan to be coming back here to the GBVRC now and then for further counseling, or to join a support group, or for any other services offered here? Tell me more about that [probe: Why/Why not?]

4. Many women at $\mathrm{KNH}$ have been asked the same questions on violence that you were asked. Some of them were referred to the GBVRC, just like you, but after being referred, they did not come to the GBVRC as recommended. You are one of those that did come. If you were asked why you decided to come to the GBVRC, what would your answer be? Kindly elaborate.

Interview Closing: That covers everything I wanted to ask. Thank you so much for your time. I've learned a lot from you today, and what you have shared will help me services better for other women with similar experiences. Do you have any questions for me? 


\section{Client Interview Guide}

\section{Assessing the Feasibility of Screening for Intimate Partner Violence (IPV) in Public Health Care Settings in Kenya \\ Population Council}

\section{For clients that were unsuccessfully referred}

Thank you so much for meeting with me today. My name is [Name]. I work with the Population Council on a project that is trying to make sure that women who have had experiences with different kinds of violence (e.g., beating by husbands/boyfriends; rape; etc.) are able to get the health care and help that they need.

We are speaking several women that were recently referred to the Gender-Based Violence Recovery Center (GBVRC) at Kenyatta National Hospital (KNH) to ask some quick questions that will help us improve women's experiences with being screened for experiences of violence at $\mathrm{KNH}$, as you were.

If you agree to speak with me, I will take about 15-20 minutes of your time, asking about your experiences with being screened for violence at the hospital, and your recommendations for improving the screening process. Everything we talk about will be totally confidential. Your name will not appear on any of our reports. I will be taking down notes as we speak to be sure I do not miss any of the important information you share with me. If at any point you would like to stop, or if there are any questions you would rather not answer, that is fine - just let me know. Is there anything you'd like to ask me at this point?

1. During a recent visit to $\mathrm{KNH}$, a provider asked you some personal questions about experiences you may have had with different kinds of violence. How comfortable would you say you felt about having the provider ask you these kinds of questions? Kindly elaborate.

- Is there another way you would suggest that such questions be posed to women in the future? Kindly elaborate.

- What did you like about the questions you were asked around violence? Just to remind you, you were asked questions about different kinds of violence, such as physical and sexual violence, and also psychological violence (e.g., being threatened, insulted, etc.).

- What did you dislike about the questions you were asked around violence?

2. How important do you think it is for women to be asked such questions regularly when they go to the hospital? Kindly elaborate.

3. After you answered the questions on violence, you were referred somewhere for further health care. Kindly walk me step-by-step through your experiences, describing how you were referred and where you were referred to.

- There are different reasons why people may end up not going for a service when they are referred. Can you tell me about your reasons for not going to where you were referred after being screened for violence?

- Any other reasons? [probe on perceptions of/experiences with the staff and the setting]

4. If you were to advise this hospital on how to encourage/motivate women to go to where they are referred to after being asked questions on violence, what advice would you give? Kindly elaborate.

\section{Interview Closing:}

That covers everything I wanted to ask. Thank you so much for your time. I've learned a lot from you today, and what you have shared will help me services better for other women with similar experiences. Do you have any questions for me? 


\section{Provider Focus Group Discussion Guide}

\section{Assessing the Feasibility of Screening for Intimate Partner Violence (IPV) in Public Health Care Settings in Kenya \\ Population Council}

Thank you so much for your willingness to take part in this group discussion. My name is [Name]. I work with the Population Council on a project that aims to assess how feasible it is to screen for IPV in public health care settings in Kenya, such as this Kenyatta National Hospital.

To help with this assessment, we are holding discussions with several groups of providers at this hospital to gain an understanding of their experiences in screening for IPV. I would therefore facilitate a discussion between you all about your own experiences in this regard so that we can understand how the screening process is working and how it can be improved.

This is very informal and the discussion will take about 45 minutes to an hour of your time. You can talk about anything you think is important for us to know. I also want to remind you that everything we talk about today is confidential. Whenever we write a report, we will use numbers rather than names in the report so no one can identify you. If there are any questions you'd rather not answer, just let me know -- that's fine.

\section{$\checkmark$ Explain the role of note-taker \\ $\checkmark$ Give a few minutes for answering any questions regarding the discussion \\ $\checkmark$ Provide ground rules for the discussion}

Remember, your answers to our questions will not be considered "right" or "wrong." They are merely information you will provide based on your experiences, observations, or feelings. Let us also remember to kindly keep everything we talk about here strictly confidential.

Before we begin, let's go round the room and introduce ourselves. You could just tell everyone which department you represent within the hospital, and your position

1. Now, all of you have had some experience with administering a screening tool to help identify women that have experienced intimate partner violence. I would like to start by asking you to share your opinions on how the screening tool is working.

o How easy or difficult would you say it is to use this tool? Kindly elaborate and provide examples.

o What about the time it takes to administer the tool - what are your experiences in this regard?

- The screening tool asks personal/intimate questions about different kinds of violence. How comfortable would you say you are with asking clients these questions? Kindly elaborate and provide examples.

2. Do you have any suggestions for rephrasing any of the questions in the screening tool so that you are/the client is more comfortable with them? Kindly give examples.

o What are your reasons for preferring that such questions be rephrased? [probe for providers' experiences with clients when asking these particular questions]

o People are different, and so different clients may react differently to the same questions. I'd like to also hear from people that have had contrasting experiences with the questions we've just discussed. Is there anyone who has asked these same questions without having a negative reaction from the client, etc.? Kindly share your experience.

3. For those of you that have had clients that actually disclosed IPV during the routine screening, how did you address the clients' needs? What did you do after making these discoveries?

- To what extent would you say the referral process (i.e., getting IPV survivors to actually go to the GBVRC) is working? Kindly elaborate.

4. Overall, do you feel that all providers in all departments would be comfortable using this tool? Why or why not? 
5. Do you feel this tool could be used within other clinical care settings (primary or secondary care institutions, for example)? Why or why not?

6. Lastly, given our interest in understanding how routine screening for IPV is working at this hospital, what should we have asked you that we didn't think to ask? [Have them respond to any question they raise].

\section{Interview Closing:}

That covers everything I wanted to ask. Thanks very much to you all for your time today. We have learned so much from you about how routine screening for IPV is working in this public health care setting. Do you have any questions for us? 


\title{
Appendix 4: Phone Script
}

\section{PHONE SCRIPT}

(FOR CONTACTING ‘NON-COMPLIANT’ CLIENTS)

\begin{abstract}
Scenario 1
Hello. May I please speak to [FIRST NAME of Respondent]?

If the person that answers the phone is NOT the Respondent:

When would be the best time to call back? DATE AND TIME
\end{abstract}

If the person that answers the phone wants to know Interviewer's identity:

This is [(First) Name]. Kindly tell [FIRST NAME of Respondent] that I called.

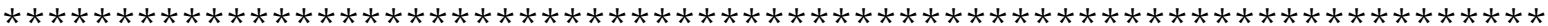

\section{Scenario 2}

Hello. May I please speak to [FIRST NAME of Respondent]?

If Respondent answers the phone: Am I speaking to [Name of Respondent]?

If yes:

How are you? I am calling from Kenyatta National Hospital. Is now a good time for me to speak with you privately?

If yes:

You are one of several that I am contacting because you had an appointment at KNH recently, and during that appointment, you were referred to the Gender-Based Violence Recovery Center at $\mathrm{KNH}$.

I wanted you to know that we are doing a study at $\mathrm{KNH}$ which involves talking to several women who were referred to the Gender-Based Violence Recovery Centre to find out their reasons for going (if they went), and their reasons for not going (if they did not go). We are trying to see what we can do as a hospital to make services available to every woman that might have experienced violence. So l'm calling to find out if you would be interested in participating in a short interview which will last about 20 minutes. If you are interested and willing to come to $\mathrm{KNH}$ for the interview, we will provide Ksh 500 at the end of the interview to reimburse you for your transportation costs. Would you be interested in participating in this brief interview?

If interested in participating, set up date, time, and venue (GBVRC):

If respondent is not interested in participating:

I understand. Thank you for your time. If you change your mind, please don't hesitate to call me. I can be reached at [phone number].

Record reason for refusal if mentioned by Respondent:

NOTES \{Jot down any info you learned during the conversation that might be a good ice-breaker for the interview.\} 


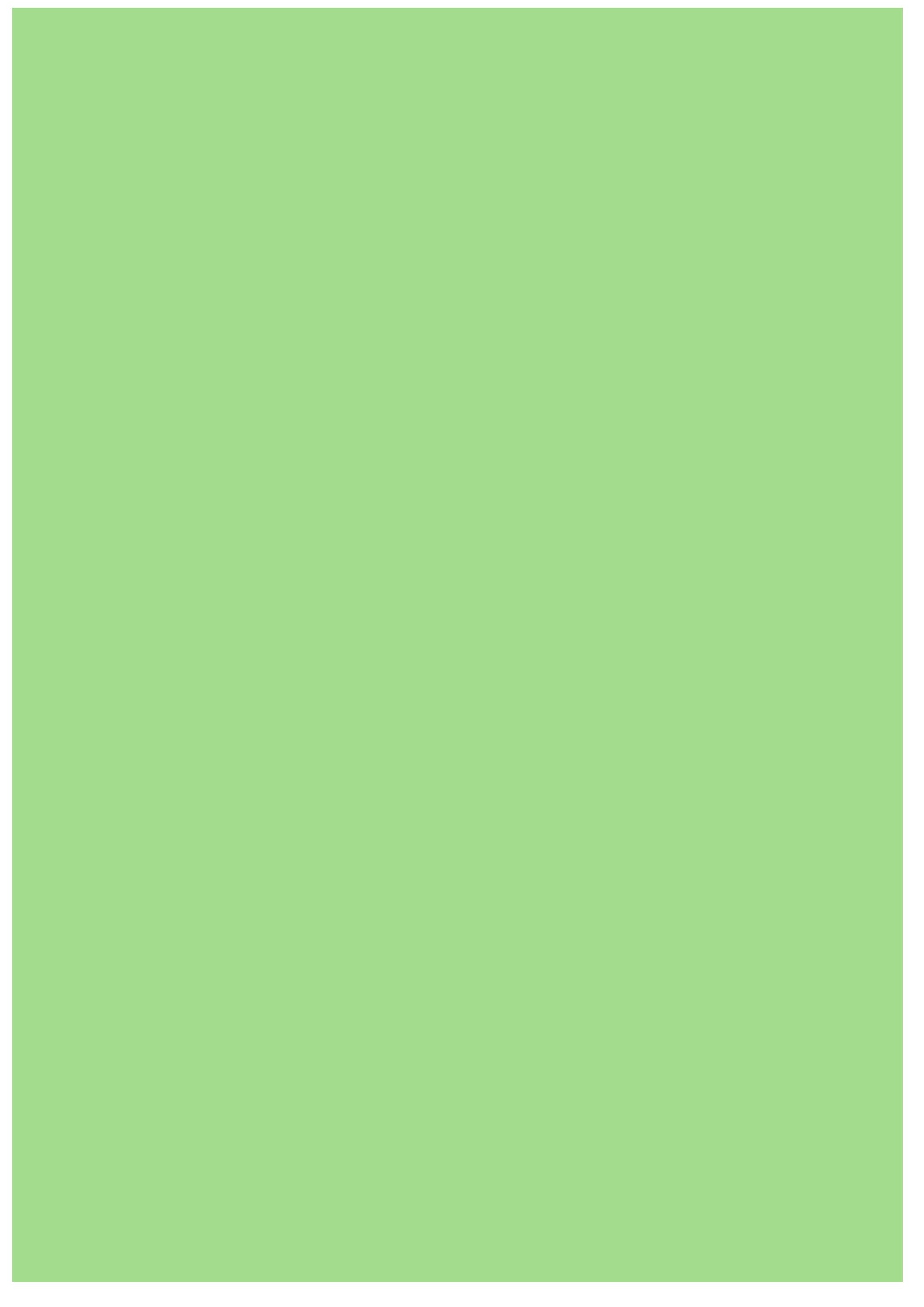

